\title{
Learning Model of Speaking Arabic: Field Research Based on Constructivism Theory at Al Muhsinin Islamic Boarding School Kerinci
}

\section{Alsuna: Journal of Arabic and English Language}

\section{Abdul Muid \\ Universitas Jambi \\ Q abdulmuid02@unja.ac.id}

\section{Sulhi Muhamad Daud Abdul Kadir}

Universitas Jambi

\section{Noza Aflisia}

Institut Agama Islam Negeri Curup

\section{Neldi Harianto}

Universitas Jambi

\section{Keywords: \\ Learning \\ Speaking Skill \\ Arabic \\ Constructivism Theory}

\section{Article Information:}

Submitted: August 18, 2020

Accepted: November 13, 2020

Approved: May 15, 2020

\section{Abstract}

Purpose - This study aimed to analyze the learning model for speaking Arabic in the perspective of constructivism theory at Al Muhsinin Kerinci Islamic Boarding School and teachers' effort in supporting the learning model used.

Design/methodology/approach - The research method used by researchers in this study was field research in descriptive qualitative.

Findings - The results showed that the learning model of Arabic speaking skills at Al Muhsinin Kerinci Islamic Boarding School studied contextual learning models consisting of daily communication activities using Arabic, quantum learning models related to independent learning activities and further learning, cooperative learning models including activities morning vocabulary learning and Arabic conversation and problem-based learning models in Arabic discussion.

Originality/value - Learning Arabic speaking skills for non-native speakers in the Boarding School needs to be constructed with complications from a compilation of various learning models.

Paper type - Research Paper

المقدمة

كانت اللغة في شكل العام هي آدة الإتصال والتعامل الإجتماعي، لذا تعليم اللغة هو تعليم عن

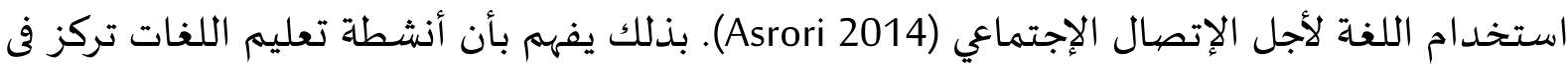

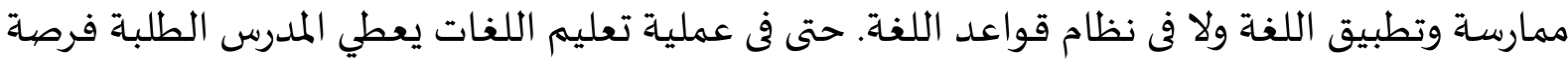
كثيرة في استخدام اللغة للإتصال مع الآخرين.

أما المكونات الأهم في تعليم اللغة خاصة الإهية تعليم اللغة العربية هي نموذج التعليم المستخدم عند معلمي اللغة العربية. هذا النموذج يشمل على المدخل وتطبيق التعليم الذى يتكون من الأهداف والمواد

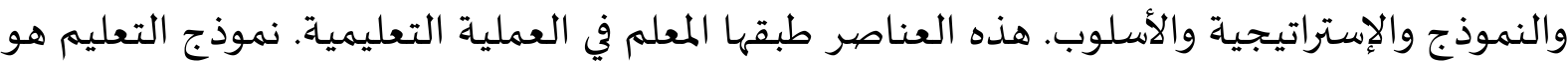


أساس تطبيق التعليم من اطار اللغة النفسي للتربية ونظرية التعليم المصمما فى ضوء التحليل على تطبيق المنهج والممارسات في المستوى الفصولية (Supriyono 2010). قال أجيب هرماوان استشهدت باه نوزا أفليسيا (2018) أن مهارة الكلام هي مهارة في تعبير أصوات

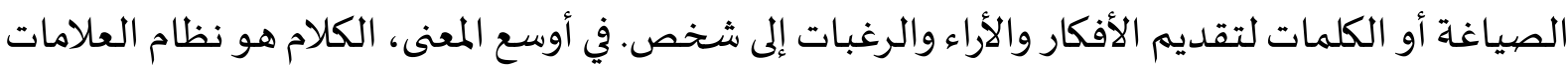

Page | 141 المسموع والمنظور تستخدم باه عضلات جسم الإنسان لتقديم الأفكار في مملوء حجاته (Aflisia 2018) .

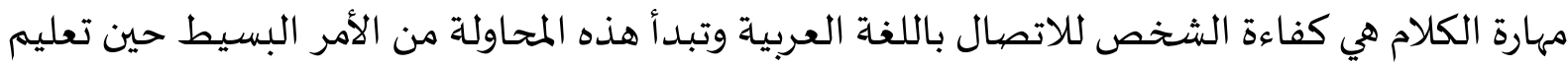

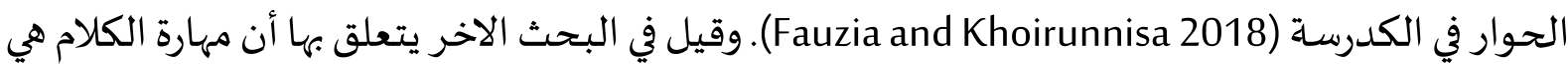

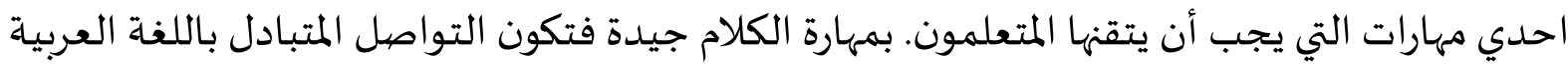

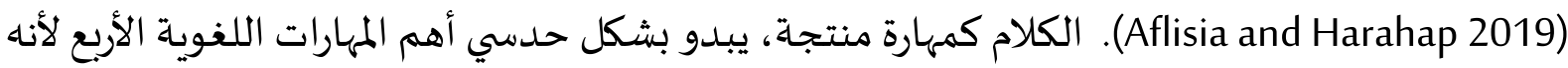

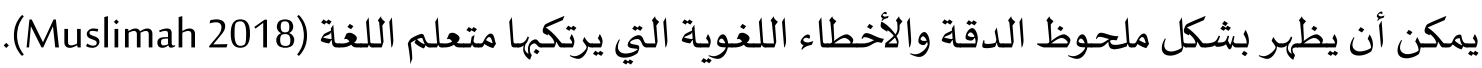

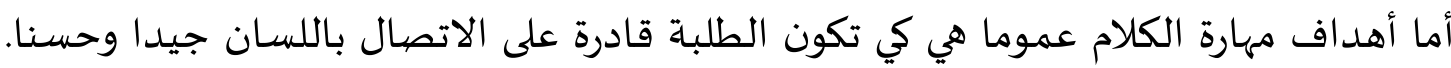

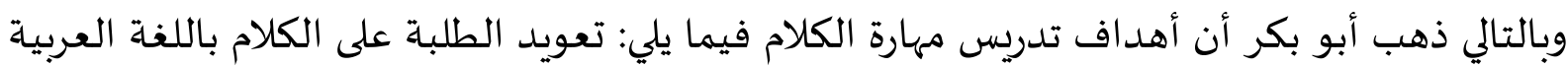

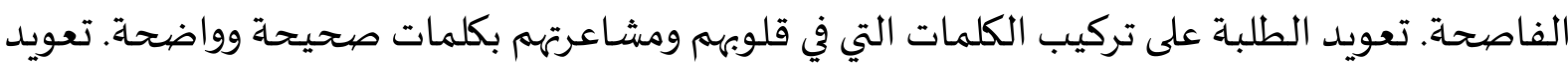

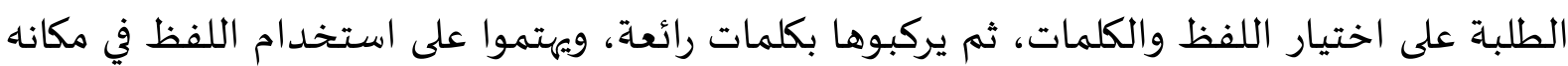

(Nuha 2012)

للحصول على نجاح التعلم في الفصل لا تنفك عن قدرة المدرس أن يطور الأنماط في تعليم مهارة

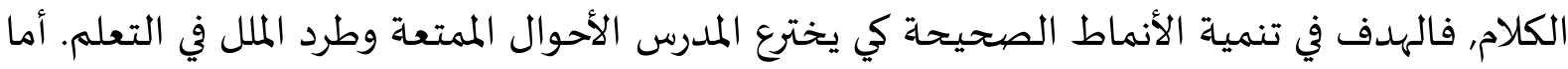

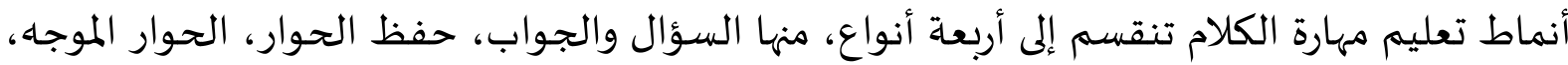

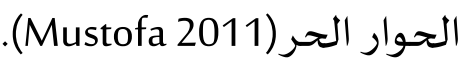

هناك نماذج ومداخل التعليم في تدريس مهارة الكلام التى طورها معلم اللغات. وكل النماذج

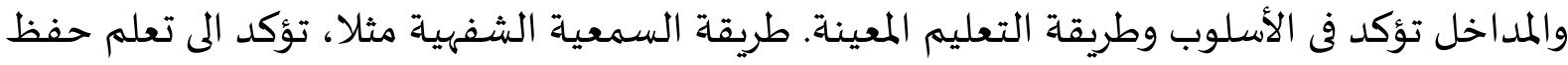

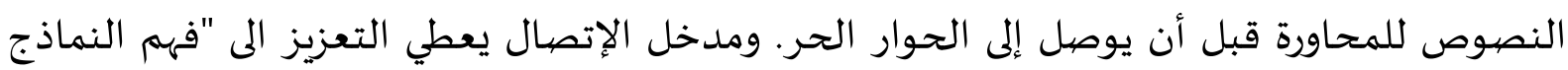

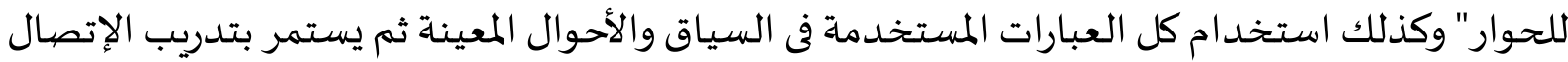

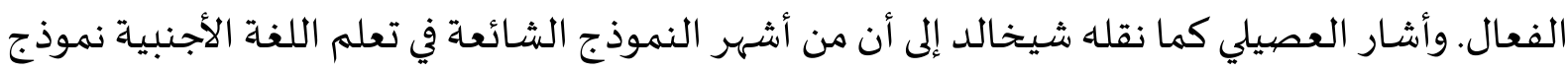



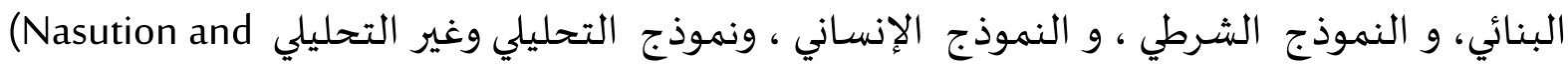
.Zulheddi 2018)

فى سياق تعليم اللغات، أرادت النظرية البنائية أن يكون الطلبة سيطرة الدرج من الدروج فى المهارات اللغوية، سواء كانت من ناحية الكفاءة والتطبيق، ويدفع الطلبة فعالة لتطوير مهاراتهم على الأفضل، لأن

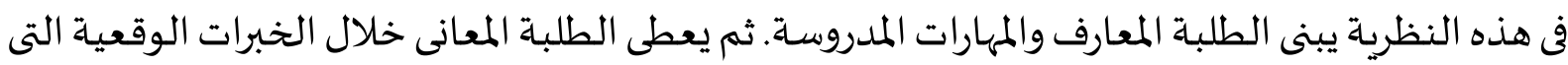
ستساعد الطلبة على بناء المعارفة خصوصا في مهارة الكلام. وفى الحقيقة، هناك كثير من المؤسسات 
الإسلامية مثل المعاهد الإسلامية، والمدارس التى تدرس فيها اللغة العربية بذاتها حيث يدرس فيها علوم اللغة

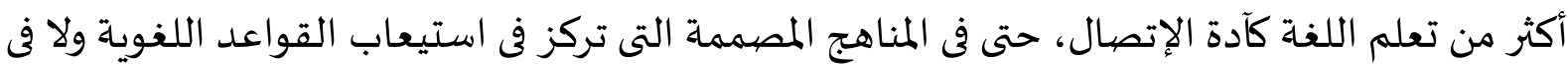
تنمية كفاءة الطلبة في مهارة الإتصال. النظرية البنائية هي سلسلة من أبنية المعرفة التي حصل الاتصال عليها واستعملها الإنسان نتيجة الاجتهاد العلمي العقلاني الناجم عن واقع التراكيب المعرفية من خلال الأنشطة التجريبية التي يقوم بها البشر في 142 | 142

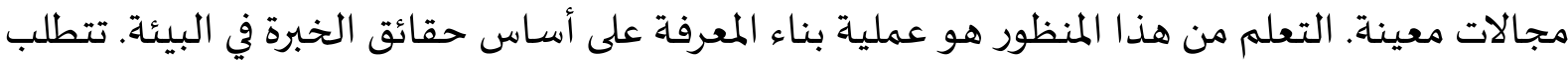
هذه العملية قاعدة معرفية صلبة لبناء المعرفة المكتسبة من خلال خبرات التعلم (Adi Widayat 2017) .

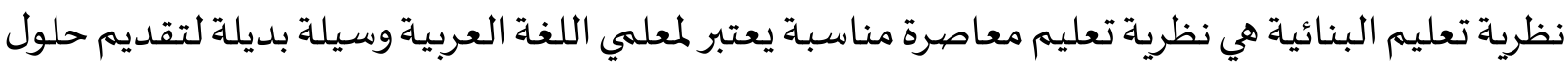
تعليمية نشطة وفعالة وخلاقة (Hamzah 2018). في عملية التعليم تمكن قول اللغة العربية التواصلية هي سمة من سماتتعليم البنائي، ويتضح ذلك الك التهاء من خلال المتعلم النشط أثناء التعليم في اكتساب معرفة جديدة في شكل لغاة والتي بعد ذلك التواصل

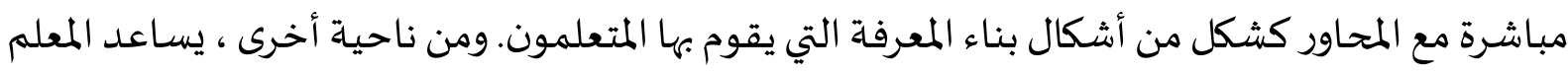
في دوره المتعلمين على بناء معرفتهم الخاصة من خلال اللغة التي يجب تعلمها (Hamdan 2019).

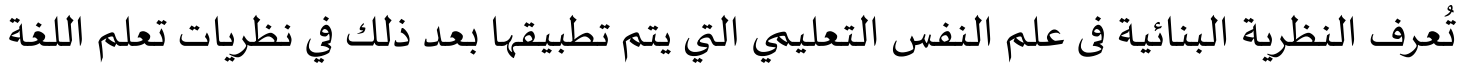

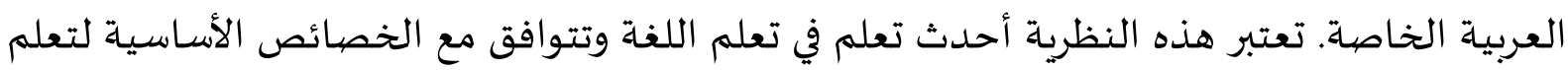

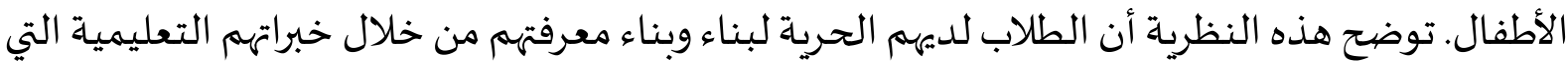

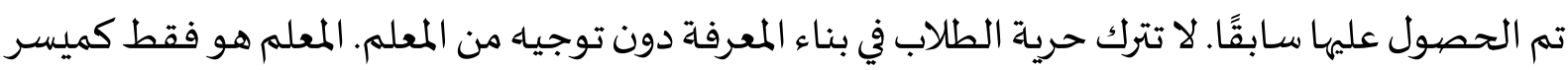

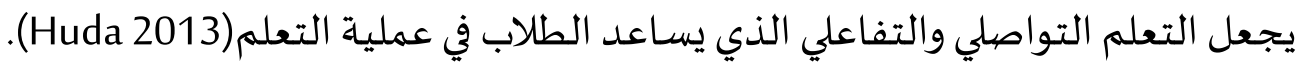

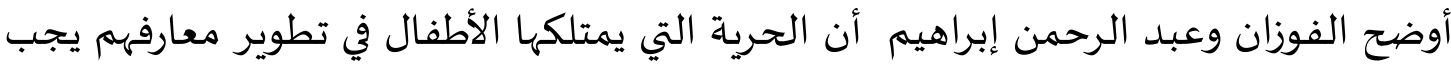

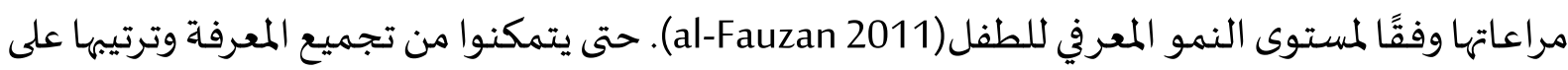

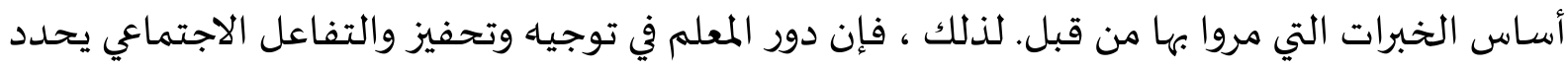

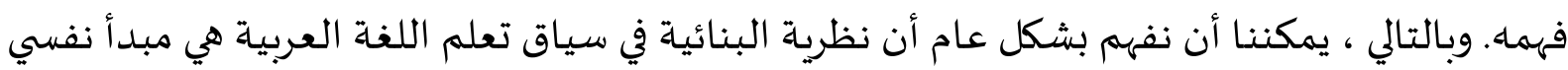

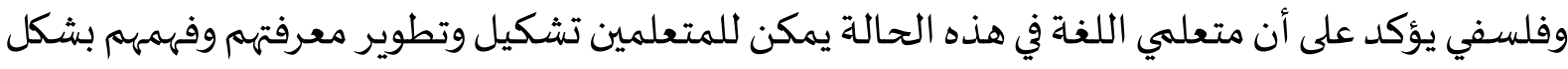

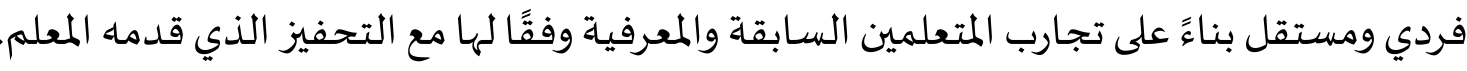

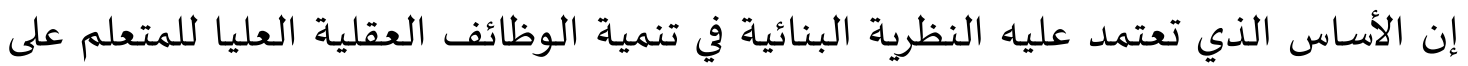

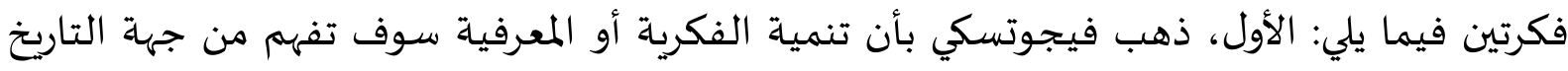

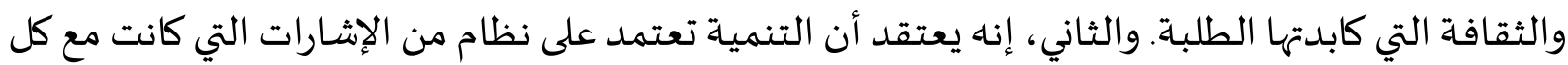

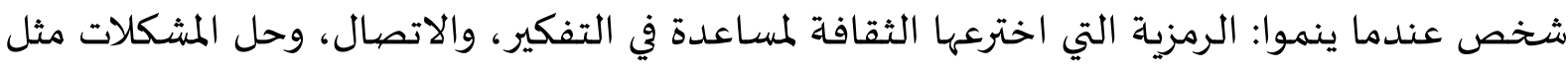

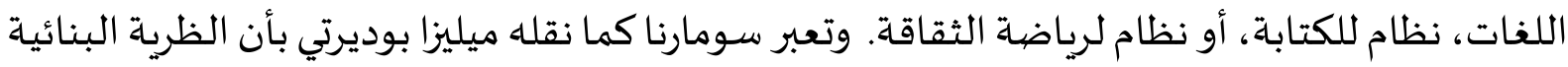

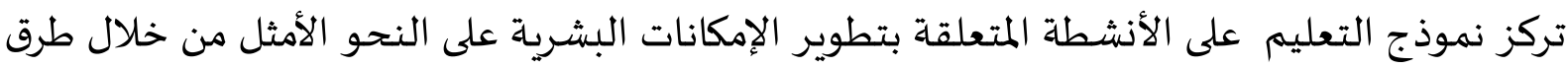
بشرية للغاية ، وهي السهولة والمرح والتمكين (Budiarti 2020). 
والأساس من النظرية البنائية يعنى: خدمة التلاميذ للتفكير عميقا، إبداع البيئة الجيدة، بناء

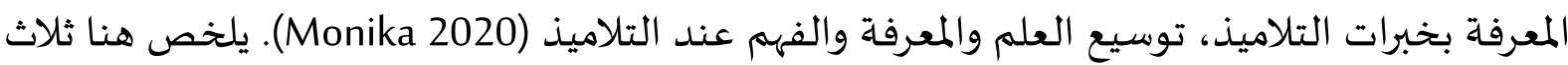
نقاط مرتبطة بنظرية الإجتماعية الثقافية فيجوتسكي وهي: إن التفاعل الاجتماعي وسيلة يتم من خلالها لمعاليا

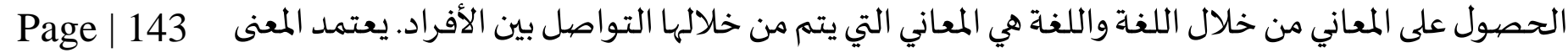

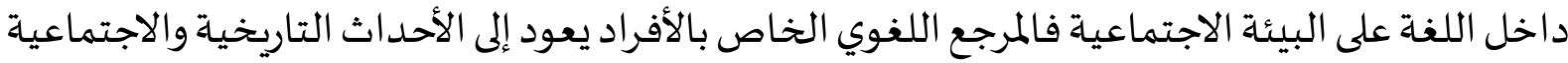

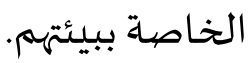

الغرض من اللغة هو استمرار العلاقات بين أفراد المجتمع ، وهذا الشكل من البنائية يركز على

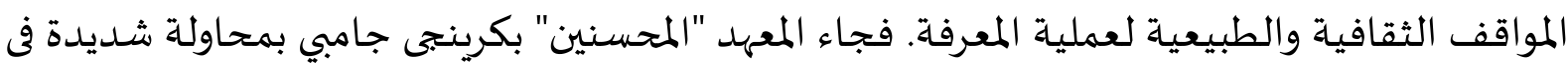

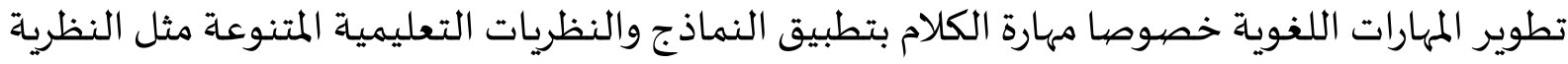

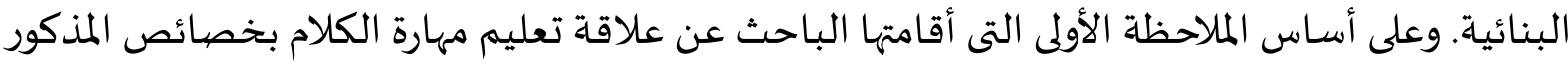

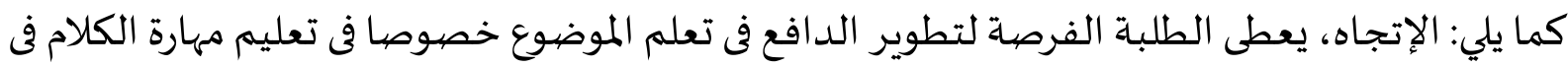
معهد المحسنين. الإستنبا، الطلبة يعبرون الفكرة خلال المناقشة والإتصال باللغة العربية وما إلى ذلك.

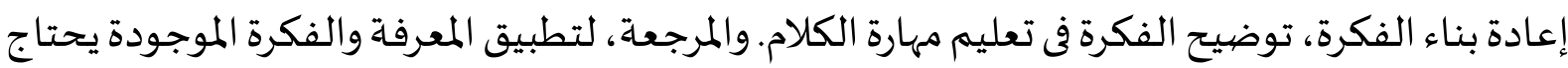
الى المراجعة والتصحيحة بالمزيدة والتبديل في تعليم مهارة الكلام. ولذا، هذه النظرية تصلح لتكون آدة آلتاء التحليل لبحث عن نماذج تعليم مهارة الكلام في معهد المحسنين.

\section{أحدث البحث وتميزه}

هناك البحوث التى أقامها الباحثون حول هذا البحث منها: ما بحثه عبد المعيد عن تعليم مهارة

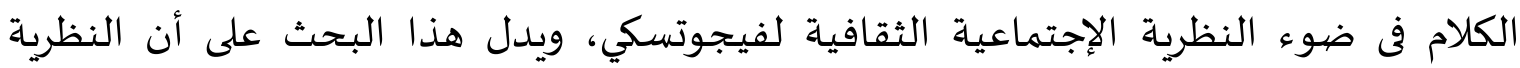
الإجتماعية الثقافية تقدم لمعلمي مهارة الكلام والمبادئ التي تمكنهم من أن يساعدوا متعلمين إلى فئل المشاركة الفعالية، والدخول في حوار نشط بين الأفراد وزملائهم حتى يصبحوا م شاركين نشطين. وكذلك هذه النظرية تقدم للمتعلمين النشاطين لهم المفزى والمواد الأصلية( Muid and Rohman

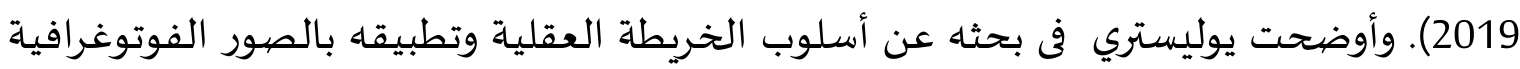

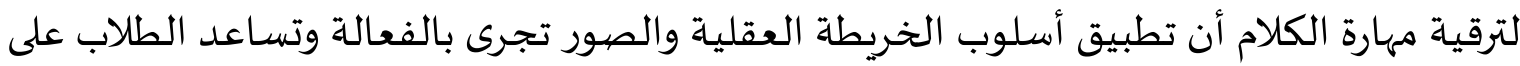

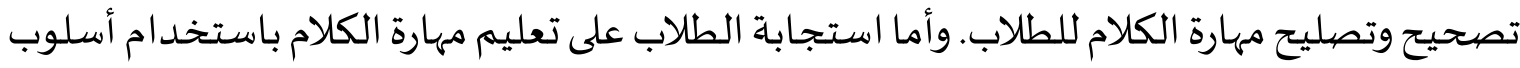
الخريطة العقلية والصهور جيد جدا (Yulistri 2015). وتعبر فترييانا وسوجى رمضنتى فى بحثها عن تعليم

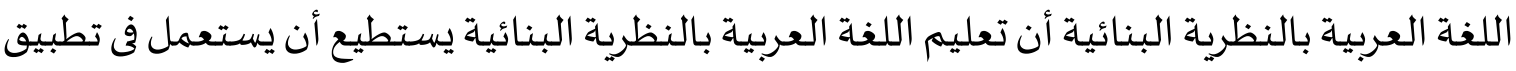
عملية تعليم اللغة العربية مفتوحة في الفصل وتؤتى الفرصة الكثيرة للتلاميذ لتحريك واختيار

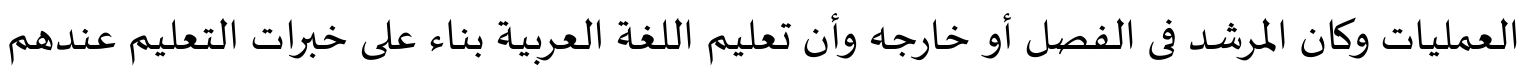

ذات معنى مباشرة (Fitriyana and Febriani 2019) 
وأضاف سوحرمون فى بحثه عن محاولة ارتقاء مهارة الكلام للطلاب بتدريب الإتصالية أن

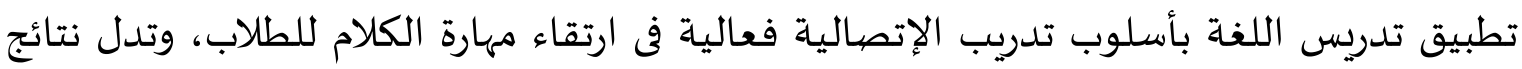
البحث على أكثر من 75\% عدد الطلاب يستطيع الكلام بالعربية سواء كانت بعبارة قصيرة أو الوتاء

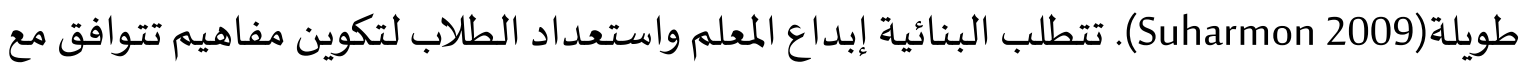

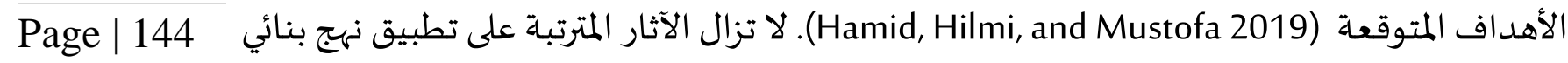

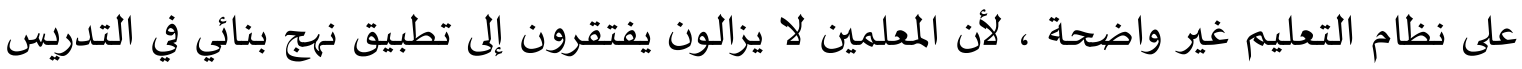

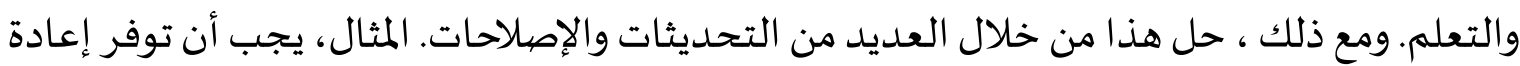

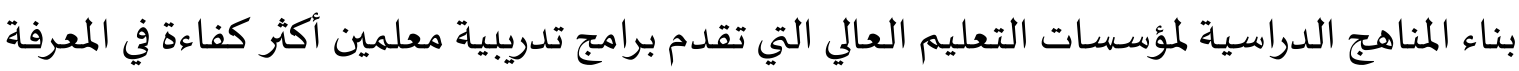
التربوية الحديثة والتطبيق العملي الراسخ (Sarina Aini Tengku Kasim et al. 2017). إن تطبيق

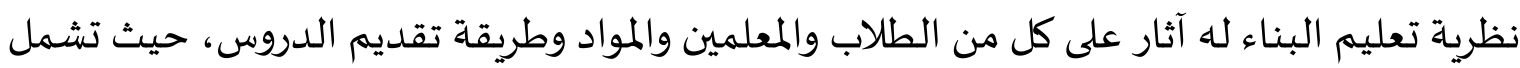
هذه الآثار عملية التعليم وعملية التدريس وتقنيات تعليم القراءة (Irawan 2014). اعتمادا على البحوث السابقة فالنظرية البنائية هي النظرية الجديدة في اتجاهات حديثة في

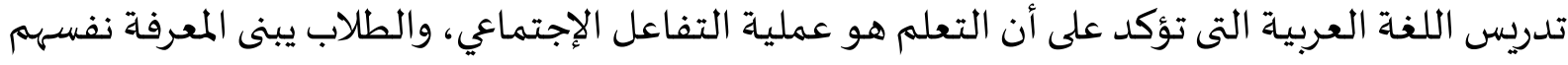

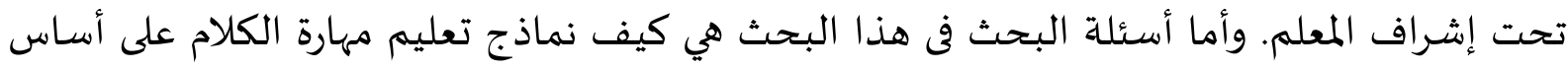

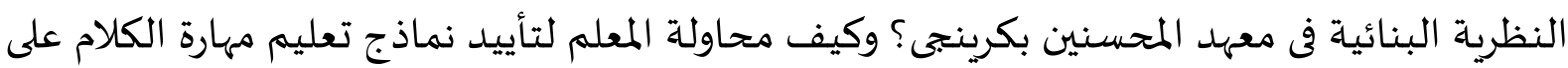
أساس النظرية البنائية فهها؟. ويهدف هذا البحث إلى معرفة نماذج تعليم مهارة الكلام على أساس النظرية

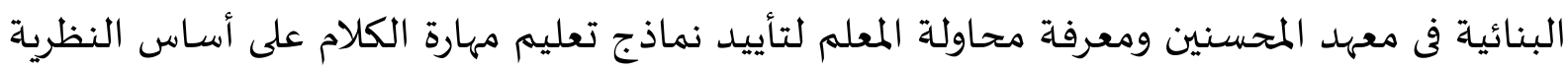
البنائية فهيا.

\section{طريقة البحث}

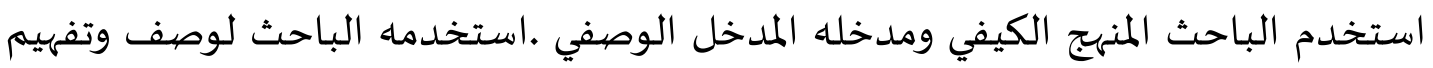

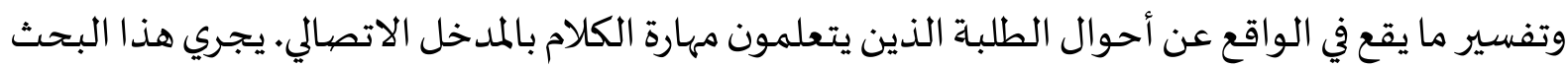

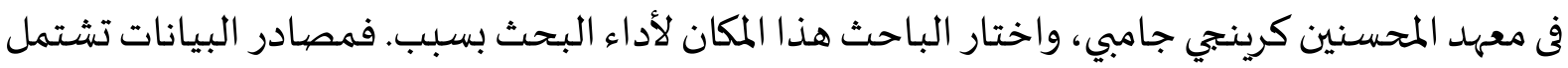

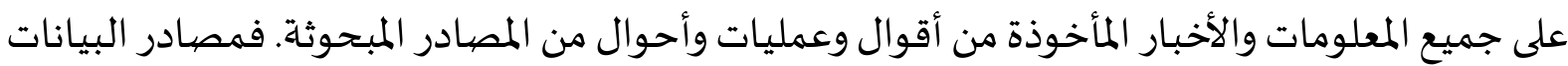

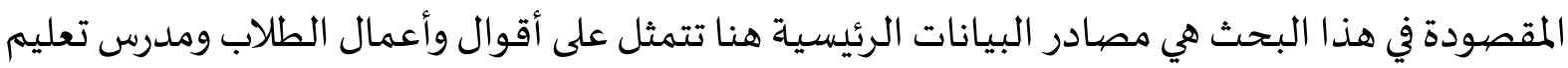

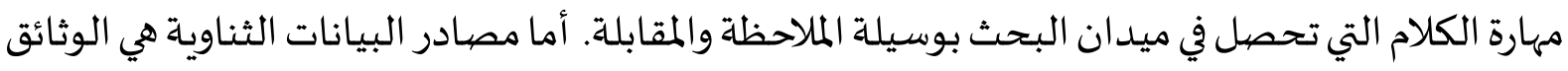
المحصيولة من الطلاب كمثل نتائج مهارة الكلام .فجمع الباحث البيانات بطريقة الماتلاحظة والمقابلة والماتلة والوثائق. تؤخذ البيانات من خطط الملاحظة، وخطط الوثائق، وخطط المقابلة. 


\section{المناقشة}

\section{نموذج التعليم التعاوني فى معهد المحسنين كرينجي}

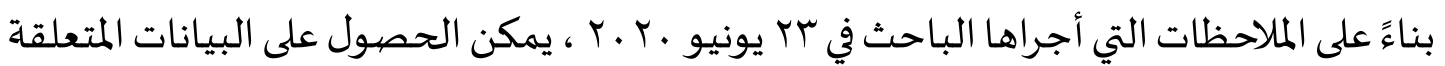

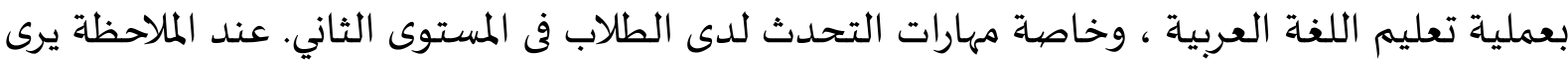

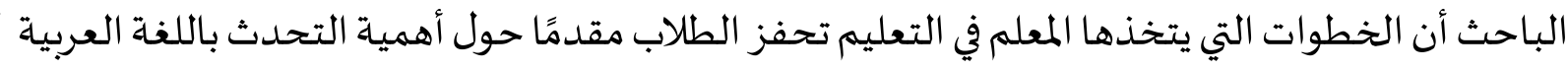
، ويتم ذلك حتى يشعر الطلاب بالاهتمام والحماس لمتابعة أنشطة التعلم التي تم إعدادها سلمابعابًا. الخطوة التالية التي اتخذها المعلم هي تقسيم الطلاب إلى مجموعات صغيرة يتم تكليفهم بالواجبات

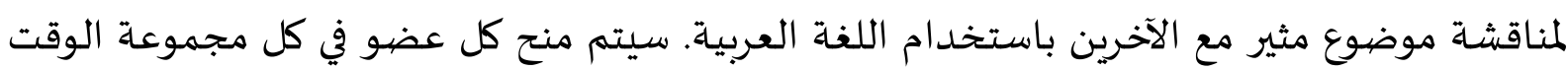

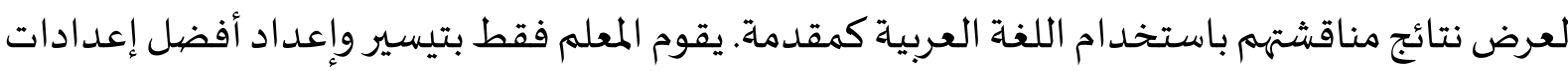

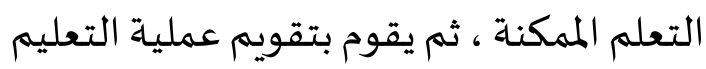

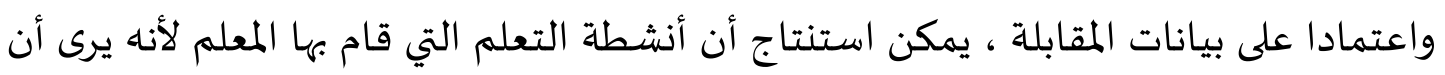

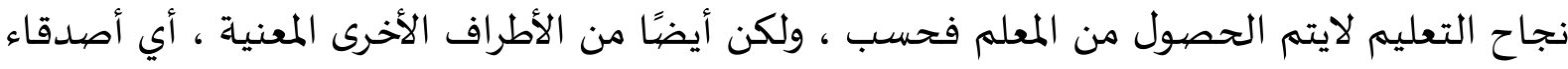

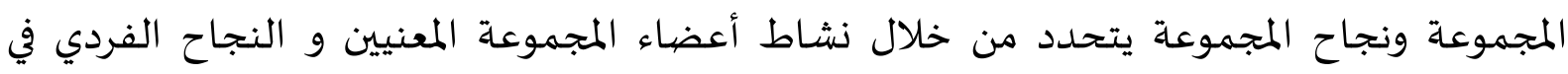

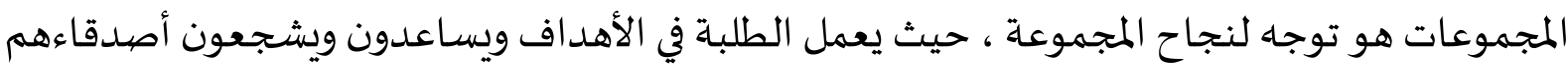

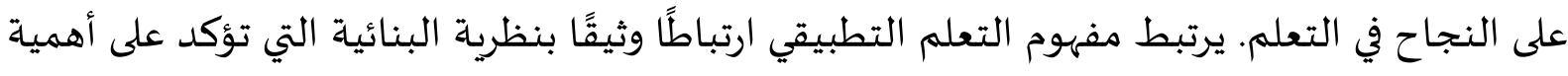

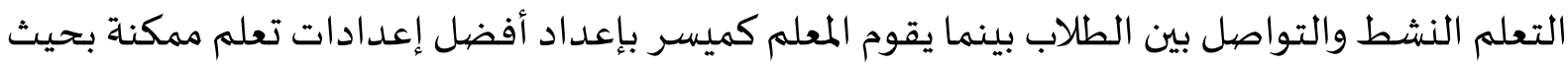
يشعر الطلاب بالراحة والمشاركة بنشاط.

\section{نموذج التعليم السياقي فى معهد المحسنين كرينجي}

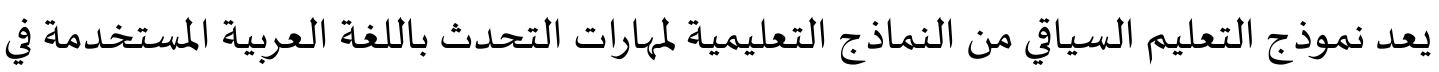

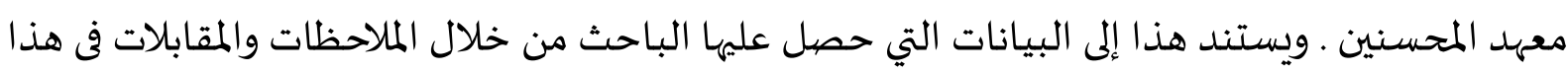
المعهد.

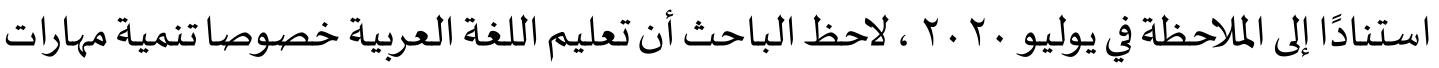

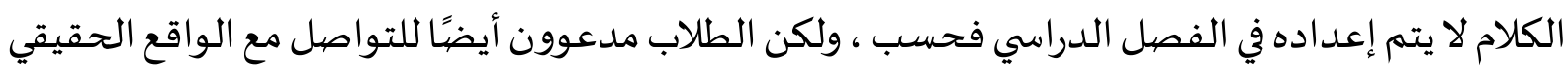

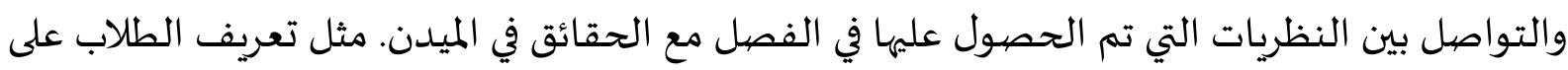

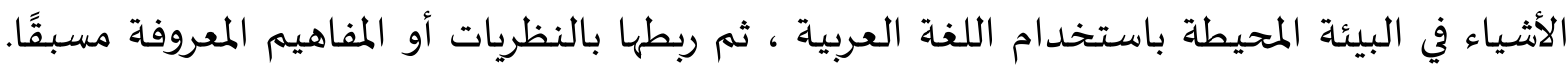

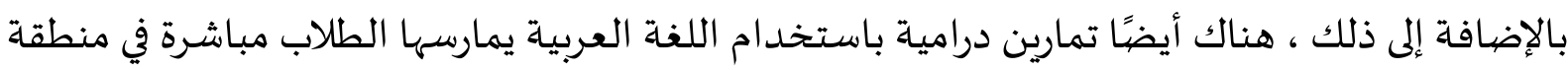

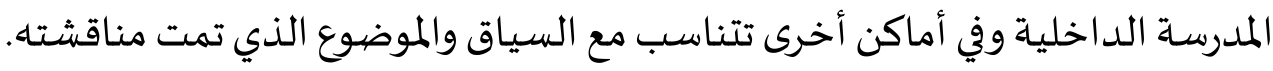

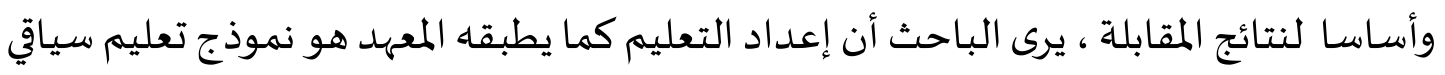

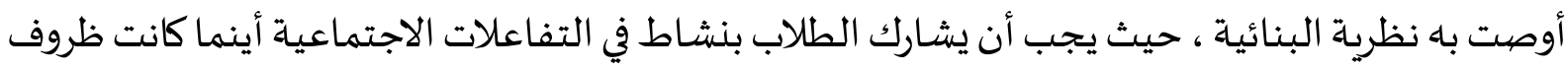

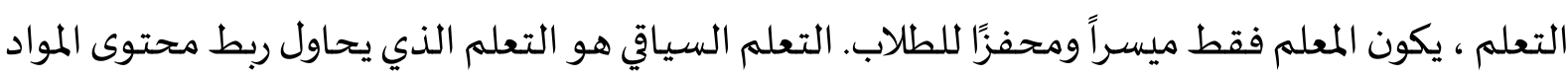


بمواقف العالم الحقيقي ويحفز المتعلمين على إقامة روابط بين المعرفة وتطبيقها في حياتهم كأفراد الأسرة والمواطنين والقوى العاملة.

Page | 146

\section{نموذج التعليم القائم على المشكلات فى معهد المحسنين كرينجي}

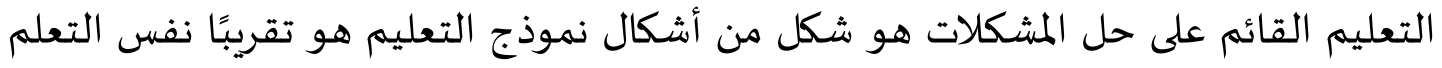

التعاوني الموجها إلى نشاط الطلبة في حل المشكلة وتوجيه الطلاب ليصبحوا متعلمين مستقلين يشاركون

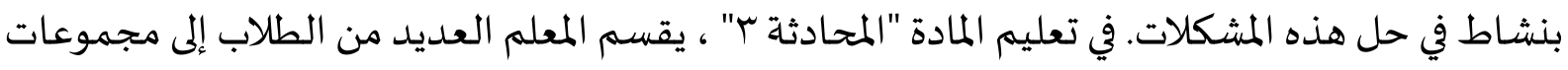

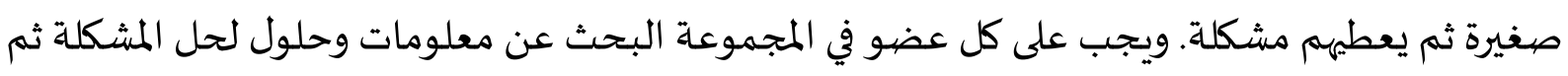

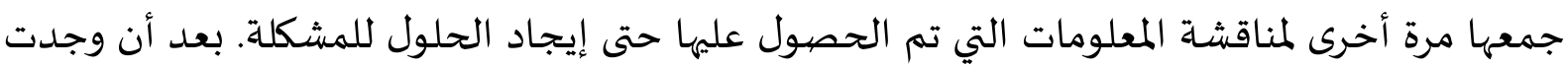

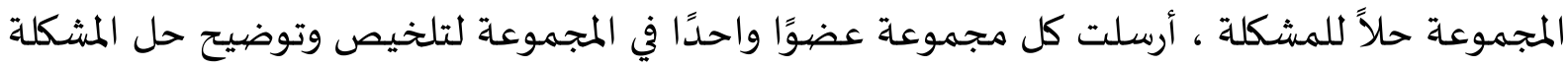

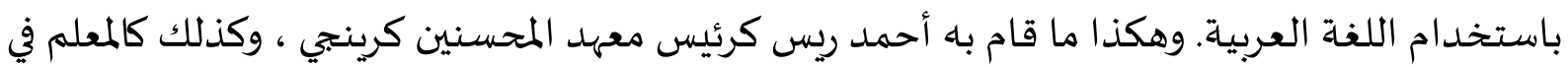
مادة المحادثة r عندما تتم عملية التعليمية. وأضيف عبد السلام كالمعلم فى مادة المحادثة أيضا عن التعليم القائم على حل المشكلات المات التالية:

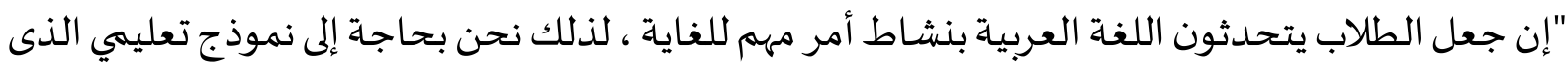

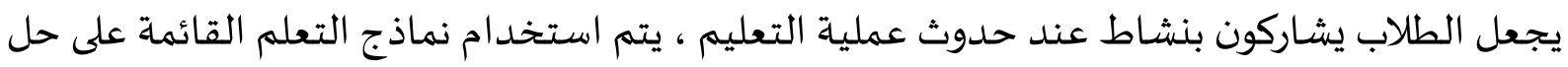

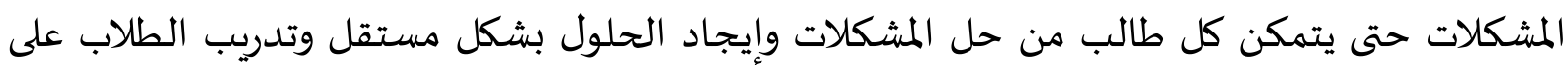

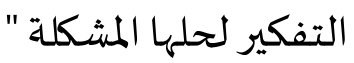

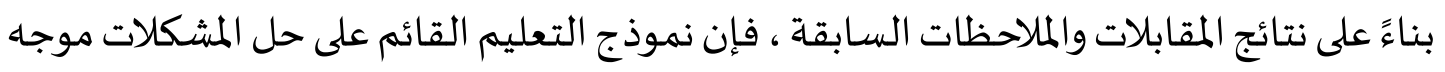
أيضًا نحو التعلم في مركز الطلاب حيث يُطلب من المتعلمين حل المشكلات ذات التفكير العالي. يتم توجيه

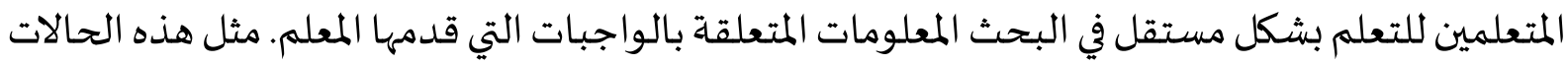

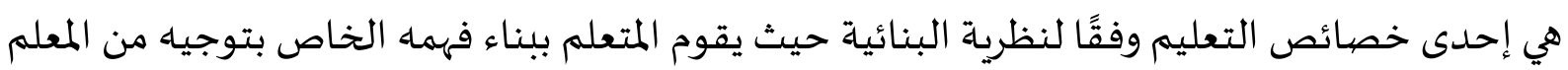
كميسر ومحفز للتعلم.

\section{نموذج التعليم الكمى فى معهد المحسنين كرينجي}

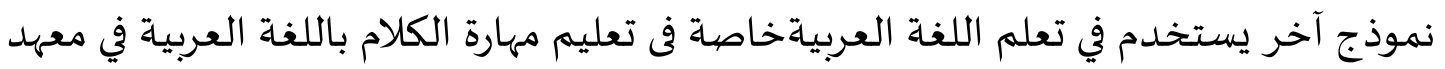

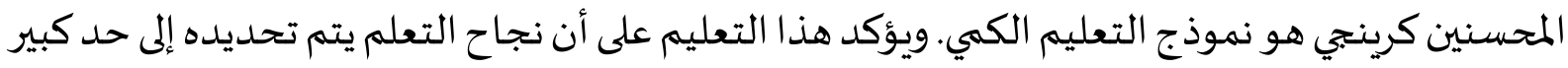

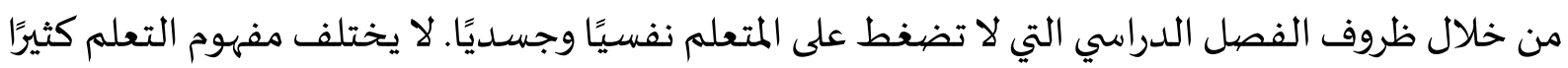
عن التعلم السياقي الذي يربط المواد التعليمية بالعالم الحقيقي المملوك للمتعلمين.

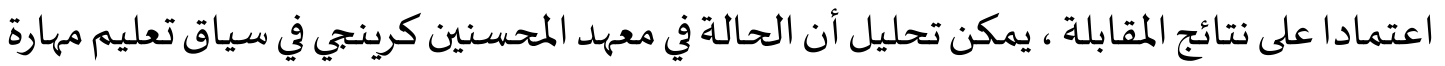

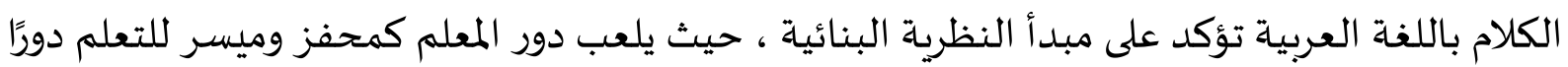
مهمًا في مساعدة الطلاب على تطوير معرفتهم وفهمهم. المعلم قادر على جعل الطلاب يجرؤون على التفاعل 
باستخدام اللغة العربية دون إكراه. كما يطبق المعلم خلال عملية التعلم تقدير التعاون بين المجموعات. هذا هو مفهوم التعليم الكمي القائم على نظرية البنائية.

Page | 147

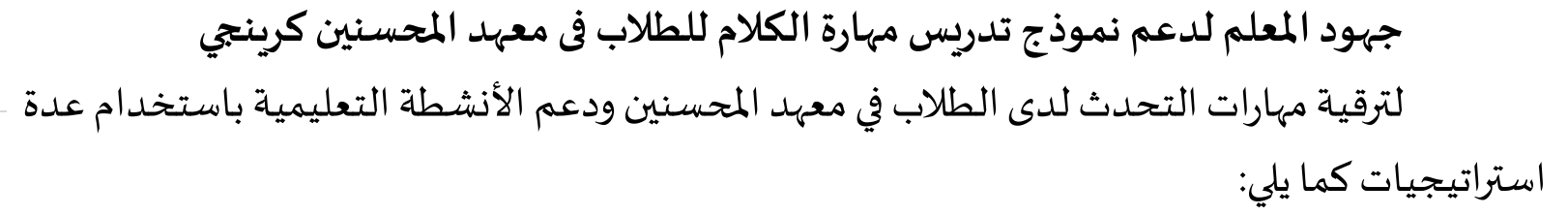

1) استيراتيجية جعل بيئة لغوية في تعليم مهارة الكلام فى معهد المحسنين كرينجي

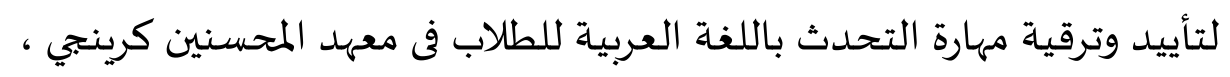

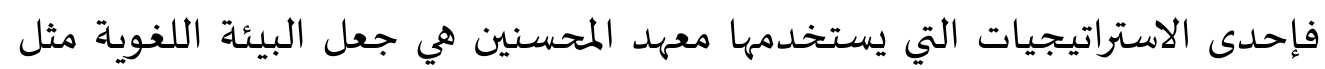

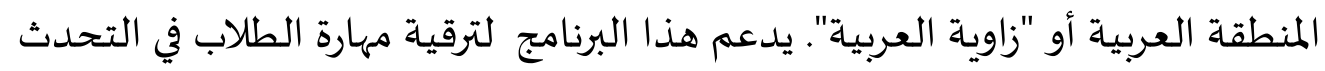

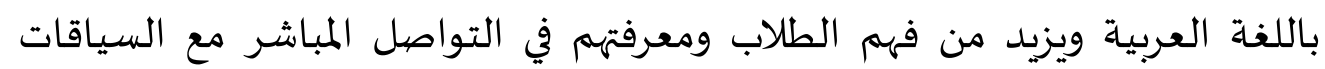
الاجتماعية.

وتم تشكيل برنامج زاوية العربية على أساس السياقية. وعلى سبيل المثال في

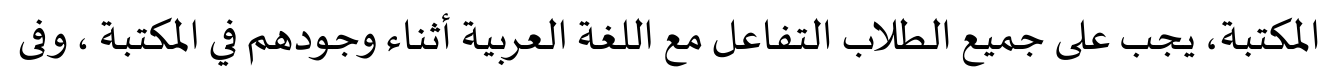

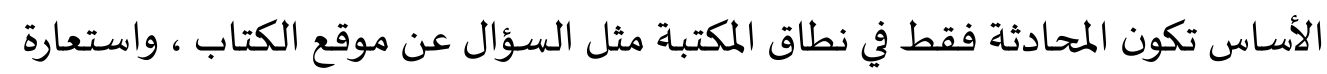

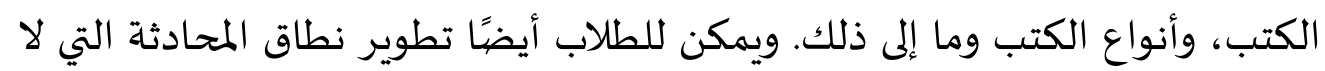

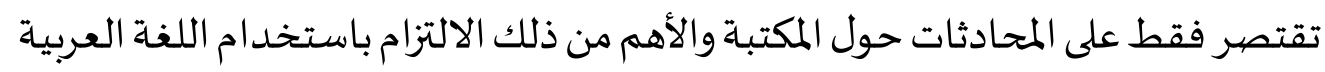

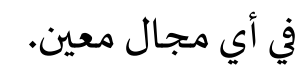
( إنشاء محكمة لغوية

في تنفيذ برنامج زاوية العربية أعلاه ، يتعين على كل طالب استخدام اللغة العربية

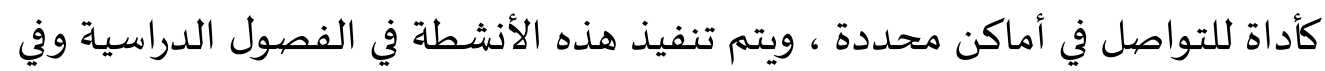

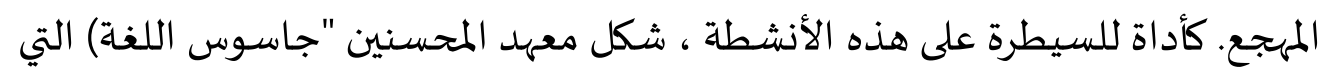
تعمل على إشراف أنشطة "المنطقة العربية".

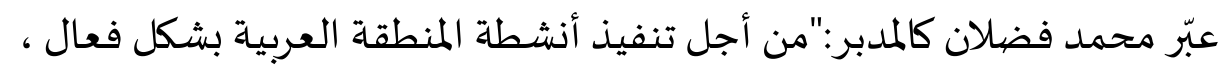

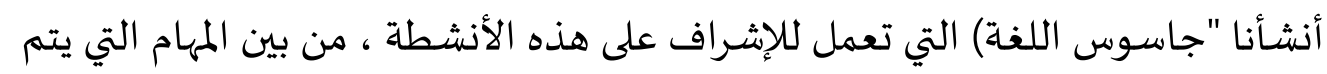

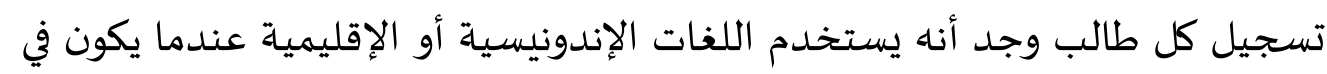

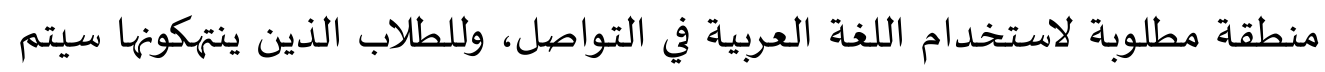
نقلهم إلى محكمة اللغة ليحاكموا ويعاقبوا حسب الدرجة الخطيئة.

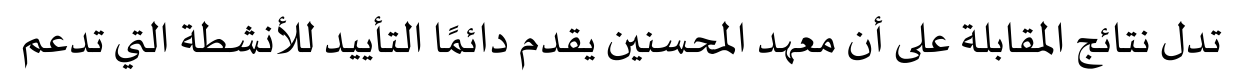

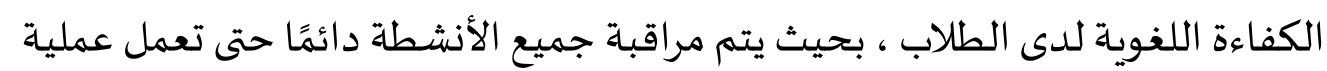


التعليم وفقًا للخطط الموضوعة ، كما يقوم بتقويم الأنشطة ، لذا، هناك التسين دائما عندما تتم عملية التعليم وبعد الانتهاء من أنشطة التعلم في نهاية الفصل المصل الدراسي.

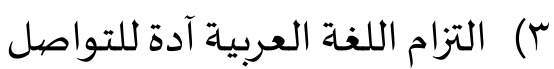

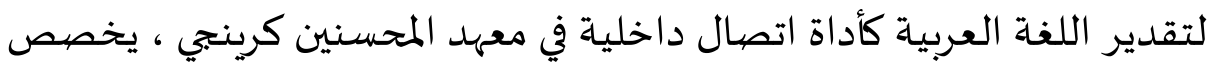

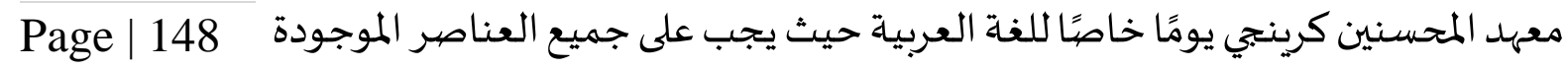

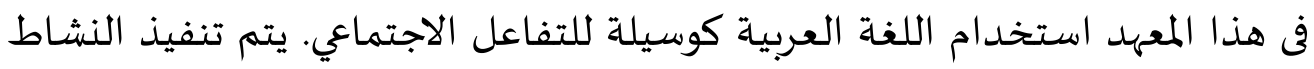

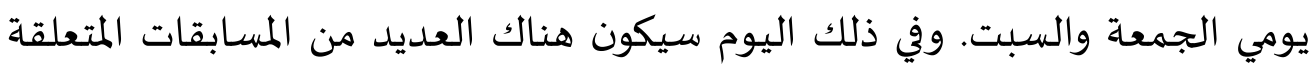
بالعربية ، مثل: الندوة العربية، الخطابة المنبرية بالعربية، والمناظرة العربية.

\section{الخلاصة}

إن نماذج تدريس مهارة الكلام على أساس النظرية البنائية المستخدمة في معهد المحسنين تتكون على أربعة تماذج وهي نموذج التعليم التعاوني والتعليم السياقي ونموذج التعليم القائم على المشكلات

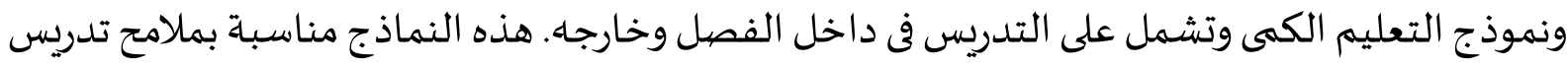

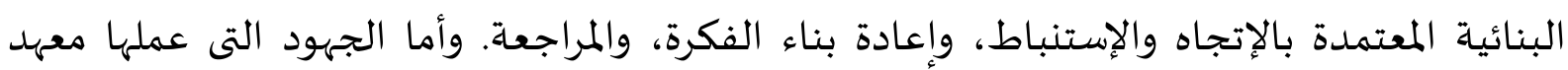

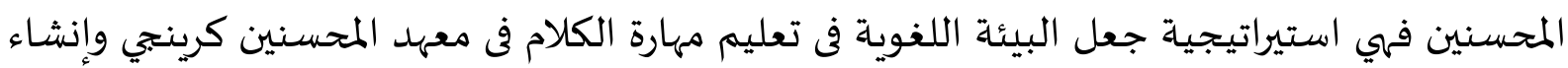

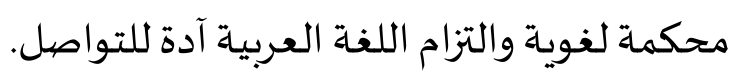

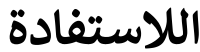

من خلال مناقشة البيانات المتعلقة بهذا البحث يمكن أن نستفيد من هذا البحث بأن نماذج

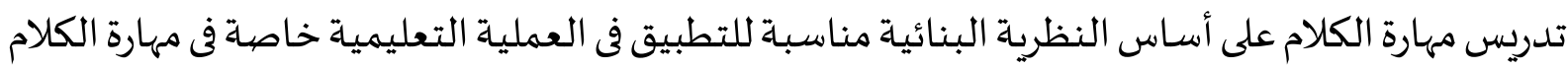

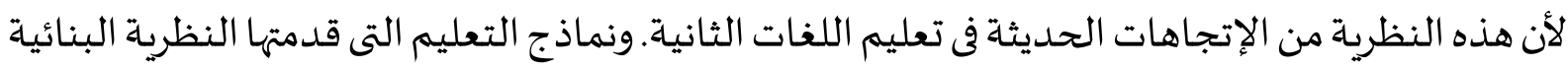

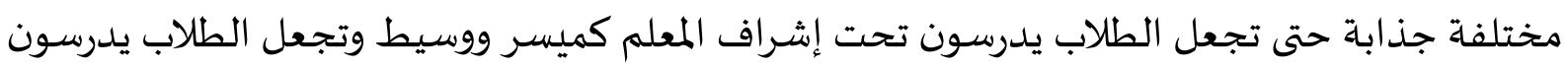
مع الأقران حتى عملية تعليم تجرى فعالة لأجل التفاعل الإجتماعي.

\section{المراجع}

Adi Widayat, Prabowo. 2017. 'Inovasi Kurikulum Bahasa Arab Madrasah Aliyah Berbasis Kontruktivisme'. An-Nabighoh.

Aflisia, Noza. 2018. 'Hubungan Antara Kemampuan Muhadatsah Dengan Nilai TOAFL Di STAIN Curup'. An Nabighoh Jurnal Pendidikan Dan Pembelajaran Bahasa Arab 19 (2): 268. https://doi.org/10.32332/an-nabighoh.v19i2.1003. 
Aflisia, Noza, and Partomuan Harahap. 2019. 'Eksistensi Biah Lughawiyah Sebagai Media Berbahasa Arab Dalam Meningkatkan Kemampuan Muhadatsah Mahasiswa Prodi Pendidikan Bahasa Arab IAIN Curup'. Lisanul' Arab: Journal of Arabic Learning and Teaching 8 (1).

al-Fauzan, Abd al-Rahman bin Ibrahim. 2011. Idhaat Li Al-Mu'allimi al-Lughah al-'Arabiyah Li Ghair al-Nathiqin Biha. Riyadh: Maktabah Malik Fahd.

Asrori, Imam. 2014. Strategi Belajar Bahasa Arab Teori \& Praktek. Malang: Misykat.

Budiarti, Meliza. 2020. 'Pembelajaran Maharah Kalam Dengan Model Quantum Learning Dalam Rangka Menghadapi Era Desruptif 4.0 Di Kalangan Milenial'. In Al-Muktamar AsSanawi Li Al-Lughah Al-Arabiyah, 43-56. Rejang Lebong: Pendidikan Bahasa Arab IAIN Curup.

Fauzia, Eva Lathifah, and Sumayyah Khoirunnisa. 2018. 'Istikhdām Uslūb Al-Ta'līm alTa'awuniy Bi Namudhaj al-Muzāwajah al-Ṣaghīrah Fī Ta'līm al-Ḥiwār Bi al-Madrasah alMutawassițah al-Islāmiyah al-Hukūmiyah 2 Bandung'. Alsuna: Journal of Arabic and English Language 1 (1): 59-68. https://doi.org/10.31538/alsuna.v1i1.66.

Fitriyana, Fitriyana Fitriyana, and Suci Ramadhanti Febriani. 2019. 'Ta'līm al-Lughah al'Arabiyah bi al-Naḍariyah al-Bināiyah'. Lisaanuna Ta`lim Al-Lughah Al-Arabiyah Jurnal Pendidikan Bahasa Arab 2

https://ejournal.uinib.ac.id/jurnal/index.php/lisaanuna/article/view/1772.

Hamdan, Muhammad. 2019. 'Kontruktivisme Pembelajaran Bahasa Arab Komunikatif'. In Konferensi Nasional Bahasa Arab V. Malang.

Hamid, M Abdul, Danial Hilmi, and Syaiful Mustofa. 2019. 'Pengembangan Bahan Ajar Bahasa Arab Berbasis Teori Belajar Konstruktivisme Untuk Mahasiswa'. Journal of Arabic Studies 4 (1): 100-114. https://doi.org/10.24865/ajas.v4i1.107. 
Hamzah. 2018. 'Kontruktivisme Dan Implikasinya Dalam Pembelajaran Bahasa Arab'. In Konferensi Nasional Bahasa Arab IV. Malang.

Huda, Miftahul. 2013. Model-Model Pengajaran Dan Pembelajaran. Yogyakarta: Pustaka

$$
\text { Pelajar. }
$$

Irawan, Ade. 2014. 'Teori Belajar Konstruktivisme Dan Implikasinya Dalam Pengajaran Membaca (Qira'ah) Bahasa Arab'. Digilib.Uin-Suka.Ac.Id. Yogyakarta.

Monika. 2020. 'Istirātījiy al-Ta'līm al-Nasyāțiy fĩ Ta'līm al-Lughah al-'Arabiyah 'alā Asās alNaḍariyah al-Bināiyah'. Lisaanuna Ta`lim Al-Lughah Al-Arabiyah Jurnal Pendidikan Bahasa Arab 3

https://ejournal.uinib.ac.id/jurnal/index.php/lisaanuna/article/view/1806.

Muid, Abdul, and M. Fathor Rohman. 2019. 'Ta'lim Maharah al-Kalaam Fi Dhu'i al-Nazhariyat al-ljtima'iyyah al-Tsaqafiyah Li Vygotsky'. Arabiyatuna : Jurnal Bahasa Arab 3 (2): 261. https://doi.org/10.29240/jba.v3i2.971.

Muslimah, Maziyyatul. 2018. 'Is Students' Speaking Participation Related to Students' Personality and Gender?' ALSUNA: JOURNAL OF ARABIC AND ENGLISH LANGUAGE 1 (1): 1-16. https://doi.org/10.31538/alsuna.v1i1.30.

Mustofa, Syaiful. 2011. Strategi Pembelajaran Bahasa Arab Inovatif. Malang: UIN Maliki Press. Nasution, Sahkholid, and Zulheddi Zulheddi. 2018. 'PENGEMBANGAN MODEL PEMBELAJARAN BAHASA ARAB BERBASIS TEORI KONSTRUKTIVISME DI PERGURUAN TINGGI'. Arabi : Journal of Arabic Studies 3 (2): 121. https://doi.org/10.24865/ajas.v3i2.96.

Nuha, Ulin. 2012. Metodologi Super Efektif Pembelajaran Bahasa Arab. Jogjakarta: DIVA Press. Sarina Aini Tengku Kasim, Tengku, Fatimah Sahida Abdurajak, Yusmini Md Yusoff, and Madiha Baharuddin. 2017. 'Pendekatan Konstruktivisme Di Malaysia Dan Brunei Darussalam: 
Satu Tinjauan Awal Terhadap Pengalaman Guru Pendidikan Islam'. Journal of Islamic Educational Research. Vol. 2. JIER.

Suharmon, Suharmon. 2009. ‘UPAYA PENINGKATAN KETERAMPILAN BERBICARA SISWA PADA

$$
\begin{aligned}
& \text { MATA PELAJARAN BAHASA ARAB MELALUI LATIHAN KOMUNIKATIF DI MTSN } \\
& \text { PANINJAUAN KABUPATEN TANAH DATAR'. Ta'dib } 11 \text { (2). } \\
& \text { https://doi.org/10.31958/jt.v12i1.156. }
\end{aligned}
$$

Supriyono, Agus. 2010. Cooperative Learning: Teori Dan Aplikasi Paikem. Yogyakarta: Pustaka Pelajar.

Yulistri. 2015. 'Uslubul Khariythah Al-'Aqliyahwa Tathbiyqihi Bi al-Shuwar al-Futughrafiyah Litarqiyati Maharati al-Kalam’. Didaktika 15. 